\title{
Editorial: Advances with the Child and Adolescent Social Work Journal
}

\author{
Bruce A. Thyer ${ }^{1} \cdot$ Lisa Schelbe $^{1}$
}

Published online: 31 July 2020

(c) Springer Science+Business Media, LLC, part of Springer Nature 2020

We, Bruce Thyer and Lisa Schelbe, began our joint appointment as new Co-Editors in 2016 and we are now completing our fifth year working on behalf of this journal, published by Springer Nature Publications, one of the world's top producers of scholarly periodicals. We have carried on the tradition of our editorial predecessors by actively soliciting high quality submissions and recruiting superlative editorial board members. These efforts have paid off.

In the world of scholarly publishing, one way of estimating a journal's quality, among others, is to see if it is listed in the Web-of-Science's Journal Citation Reports' (JCR) database owned by Clarivate Analytics. Of the several hundred social work journals around the world, only 42 make this list. Being listed on the JCR means that a given journal has received an impact factor (IF). A given journal's impact factor is calculated by counting the number of research papers that journal has published in the past 2 years, and dividing this by the number of times these articles have been cited during that 2 year window. The higher a journal's IF, the more likely it is that its articles will be cited, which is a very direct measure of scholarly impact. One way to enhance the likelihood your own publications will be read and cited, is to publish in a journal with an IF, and the higher the IF the better, in terms of use within the discipline. While not all highly cited articles reflect genuinely good research (the work could simply be about something controversial, or contain an egregious mistake that others cite as a bad example, etc.), in general authors like to see their publications cited a lot, hence the attractiveness of publishing in a journal with a high IF.

We are very pleased to announce that this year the Child and Adolescent Social Work Journal (CASWJ) was added to the JCR, receiving an IF of 1.156. In this instance, the CASWJ published 111 articles during 2018 and 2019, and these articles were cited in 96 other publications

Bruce A. Thyer

bthyer@fsu.edu

1 Florida State University, Tallahassee, FL, USA
$(111 / 96=1.156)$. Our initial impact factor exceeded that of many other well-established social work journals long-listed in the JCR, including the NASW journal called Social Work Research, the CSWE's Journal of Social Work Education, and the Clinical Social Work Journal, among others. The CASWJ was ranked \#24, in terms of 2 year IF, right in the middle of the social work journals listed. We are actually better than that since for some reason the JCR incorrectly includes some non-social work journals in its social work list, periodicals such as the American Journal of Orthopsychiatry, and the American Journal of Community Psychology. Were these inappropriately included journals removed from the social work listing, the rank of the CASWJ would be higher still. Social work journals' IFs are not static. They are recalculated every year and posted in the JCR. Accordingly, IFs for a given journal can rise and fall over time but generally, journal publishers and editors (such as ourselves) like to see their journals' IF increase over the years.

One consequence of obtaining an impact factor like this is that authors seeking a wider readership for their work will be more likely to submit to this journal. Having more submissions generally means we can be more selective in the papers we accept, elevating the quality of the research we publish. As it is, we accepted less than $32 \%$ of submissions during the first half of 2020, which is fairly selective. Another way to evaluate readership are the number of articles downloaded from the journal's website. In 2019, for example, we had 158,950 article downloads. Obviously, journals with greater numbers of downloaded articles are attracting more interest than ones with fewer downloads. Another sign of a journal's quality is that it has input from social workers around the work. We are pleased that the CASWJ is international in scope. Our recent authors reflect contributions from social work scholars around the world, including countries such as Canada, Portugal, China, Israel, South Africa, and Sweden, among others. Our current editorial board reflects this international diversity, with members living in Israel, Hong Kong, the Czech Republic, South Africa, and Taiwan being represented. 
A journal's IF is not a perfect measure of its quality, as pointed out recently by Marson (2020) and Thyer (in press). There are ways Editors can 'game the system' and artificially inflate their journal's IF. One way is to include an Editor's editorial in each issue that lists and cites every article appearing in that new issue. This common practice artificially increases the journal's IF. Here at the CASWJ we are above such sordid machinations. Another potential problem is the practice in many countries, across diverse disciplines (including social work), of program directors providing a financial bonus to faculty who publish in a high-impact journal, or for them to tell faculty to not bother publishing in journals without an IF, as such publications will minimally count towards one's credible promotion and tenure oeuvre.

The decision making process used by Clarivate Analytics to choose which journals to include in the list of social work periodicals listed in the JCR is completely opaque. There is no public algorithm or set of rules governing this process, which mitigates against a fundamental principle of science, that of transparency. In effect, our profession has no control over what journals are designated as social work journals within the JCR. While these blemishes on the face of scholarly publishing are regrettable, we can nevertheless take pride in the hard work of the journal's editorial board. This made possible the CASWJ earning its place among social work journals with an IF. This is one benchmark, among several, reflecting on the quality of the articles appearing in this journal, and worth noting, if indeed not celebrating. Jensen (in press) happily noted that the Journal of the Society for Social Work and Research obtained an impact factor and earned its place on the JCR in 2016. We are delighted that the CASWJ has accomplished the same achievement. Of course the best way to measure a given article's research quality is not by judging the journal it was published in but by actually reading and critically analyzing individual studies.

On another matter, we note that 2018 saw the appearance of the 7th edition of the Publication Manual of the American Psychological Association (American Psychological Association, 2018), which we are now using. Apart from the usual tweaks and burnishing, the new manual contains a series of Journal Article Reporting Standards (JARS) for researchers to use in preparing their research and in writing it up for submission to scholarly journals. There are separate JARS for quantitative research (Appelbaum, Cooper, Kline, Mayo-Wilson, Nezu, \& Rao, 2018) and qualitative primary, qualitative meta-analytic, and mixed-method research (Levitt, Bamberg, Creswell, Frost, Josselson, \& Suárez-Orozco, 2018), and here at the CASWJ we ask our authors to adhere to these guidelines as closely as possible, either in their initial submission to the journal, or if we ask them to prepare a revision. The JARS were authored by leading research methodologists in their respective fields, and we encourage social work scholars are all levels, from doctoral students to senior faculty, to become familiar with and follow these guidelines. Doing so will help ensure the complete reporting of essential information, which aids reader comprehension and enhances the possibility of others reanalyzing or replicating your research. Wharton (2015) provides a positive perspective on the contributions guidelines such as the JARS can make to improving the quality of social work research.

Touching on APA style, we could like to caution potential authors against a problem we commonly encounter in initial submissions to social work journals. Namely, researchers sometimes use papers published in journals as their guide to APA style. This is a serious mistake because there are many significant differences between formatting a journal manuscript for submission and review by a journal, and how an article looks like once it is accepted and appears in an online or print issue. The APA manual is a guide to preparing manuscripts for submission to a journal and should be strictly followed. Using published papers as one's guide may lead to significant errors. We also do not recommend any other sources on how to follow APA style, apart from the APA manual itself, or other official guidance provided by the APA online (e.g., https://apastyle.apa.org/). Cooper (2020) and Levitt (2020) are small books exclusively devoted to following the Journal Article Reporting Standards for quantitative and qualitative research, respectively, and we highly recommend them as supplements to being very familiar with the APA manual itself, and would make good auxiliary textbooks for doctoral students.

We look forward to continued enhancements to the CASWJ via more high-quality submissions, rigorous blind peer review, and even more timely decision-making and publication schedules. We invite you to consider submitting clinical and research articles for publication to this journal. Thanks to our new impact factor you can be assured your work will be widely disseminated world-wide to our growing international readership. You can also offer to write a book review for us, related to the scope of this journal, and you can consider guest editing a special issue on a relevant topic. As always, we invite your feedback and suggestions to make the CASWJ a more useful publication for the social work field and other professionals concerned about promoting a research-supported approach to human services.

\section{References}

Appelbaum, M., Cooper, H., Kline, R. B., Mayo-Wilson, E., Nezu, A. M., \& Rao, S. M. (2018). Journal article reporting standards for quantitative research in psychology: The APA Publications and Communications Board task force report. American Psychologist, 73, 3-25. 
Cooper, H. (2020). Reporting quantitative research in psychology: How to meet APA style Journal Article Reporting Standards (2nd ed., revised). Washington, DC: American Psychological Association.

Jensen, J. (in press). Reflections on the Journal of the Society for Social Work and Research. Journal of the Society for Social Work and Research.

Levitt, H. M. (2020). Reporting qualitative research in psychology: How to meet APA style Journal Article Reporting Standards (revised ed.). Washington, DC: American Psychological Association.

Levitt, H. M., Bamberg, M., Creswell, J. W., Frost, D. M., Josselson, R., \& Suárez-Orozco, C. (2018). Journal article reporting standards for qualitative primary, qualitative meta-analytic, and mixed methods research in psychology: The APA Publications and Communications Board task force report. American Psychologist, 73(1), 26-46.
Marson, S. M. (2020). Editorial: Is the Impact Factor (IF) ethical to use for promotion and tenure decisions? Journal of Social Work Values and Ethics, 17(1), 2-5.

Thyer, B. (in press). Journal Impact Factors: The good, the bad and the ugly. Journal of Social Work Values and Ethics.

Wharton, T. (2015). Rigor, transparency, and reporting social science research: Why guidelines don't have to kill your story. Research on Social Work Practice, 27, 487-493.

Publisher's Note Springer Nature remains neutral with regard to jurisdictional claims in published maps and institutional affiliations. 